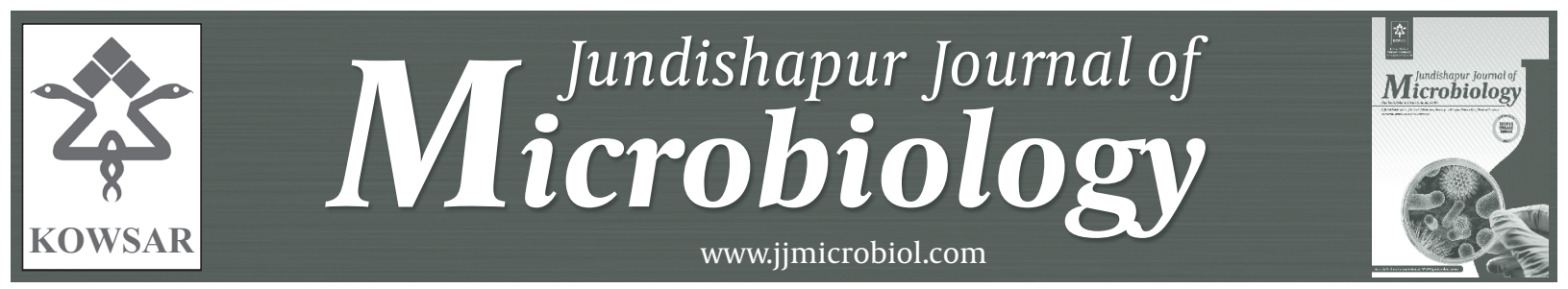

\title{
Relative Frequency of Seasonal Influenza A and B in Khuzestan Province by Reverse Transcription-Polymerase Chain Reaction (RT-PCR) During 2009- 2010
}

\author{
Zamaneh Hajikhezri ${ }^{1, *}$, Manoochehr Makvndi ${ }^{1}$, Ali Reza Samarbaf-zadeh ${ }^{1}$, Niloofar Neisi ${ }^{1}$, \\ Kambiz Ahmadi $^{2}$ \\ ${ }^{1}$ Department of Medical Virology, School of Medicine, Jundishapur University of Medical Sciences, Ahvaz, IR Iran \\ ${ }^{2}$ Department of Statistics, School of Medicine, Jundishapur University of Medical Sciences, Ahvaz, IR Iran \\ ${ }^{*}$ Corresponding author: Zamaneh Hajikhezri, Department of Medical Virology, School of Medicine, Ahvaz Jundishapur University of Medicine, Ahvaz, IR \\ Iran. Tel:+98-6113330074, Fax: +98-6113332036, E-mail: zamanehhajikhezr@yahoo.com.
}

\begin{abstract}
A B S T R A C T
Background: Influenza A and B viruses are the major causative agents of human respiratory infections, and these viruses are responsible for considerable mortality and morbidity around the world.

Objectives: The objective of this study was to determine the frequency of influenza among suspected patients with influenza-like syndrome by RT- PCR assay in Khuzestan province of Iran during 2009-2010.

Patients and Methods: Nasopharyngeal swabs were collected from 655 suspected patients with influenza-like syndrome in Khuzestan province Iran from March 2009 to February 2010. Clinical samples were taken within the 48 hours of initial symptoms, and were stored at -70 ${ }^{\circ} \mathrm{C}$. The patients were between 1 month and 85 years old. Initially all samples were tested for Influenza A and B viruses. Subsequently, for those samples with positive results for influenza A virus, influenza A/H3N2, and A/H1N1 tests were performed. The total assays were performed using RT-PCR.

Results: Of 655 samples, 69 (10.53\%) had positive results for human influenza A virus, and 5 (0.7\%) samples had positive results for influenza B. Of those 69 samples with positive results for influenza A viruses, 45 (6.8\%) were H3N2, and 24 (3.6\%) were H1N1 subtypes. In this study most cases with positive results were less than 20 years. The sample positive included $49 \%$ males and $51 \%$ females. The peak seasonal influenza was between October and December 2009.

Conclusions: This finding showed that the predominant subtype of influenza virus among patients is A/H3N2, followed by A/H1N1 and B in Khuzestan province during the 2009-2010.
\end{abstract}

Keywords: Influenza A virus; Influenza B virus; Khuzestan

Copyright (C) 2013, Ahvaz Jundishapur University of Medical Sciences; Published by Kowsar Corp.

Article type: Research Article; Received: 28 Apr 2012; Revised: 17 Jul 2012; Accepted: 08 Aug 2012; Epub: 01 Jun 2013; Ppub: Jun 2013

Implication for health policy/practice/research/medical education:

Since prevalence of influenza virus was not determined in khuzestan, this study improves our epidemiological knowledge about the significance of prevalence of influenza.

-Please cite this paper as:

Hajikhezri Z, Makvndi M, Samarbaf-zadeh AR, Neisi N, Ahmadi K. Relative Frequency of Seasonal Influenza A and B in Khuzestan Province by Reverse Transcription-Polymerase Chain Reaction (RT-PCR) During 2009-2010. Jundishapur J Microbiol. $2013 ; 6(4)$ :e5312. DOI: $10.5812 / j j m .5312$.

Copyright (C) 2013, Ahvaz Jundishapur University of Medical Sciences; Published by Kowsar Corp.

This is an Open Access article distributed under the terms of the Creative Commons Attribution License (http://creativecommons.org/licenses/by/3.0), which permits unrestricted use, distribution, and reproduction in any medium, provided the original work is properly cited. 


\section{Background}

Influenza A and B viruses are the major causative agents of acute respiratory infection, responsible for a high level of morbidity and mortality, particularly among infants, elderly, individual with pulmonary and cardiac diseases, diabetes, and patients with immunocompromised status worldwide $(1,2)$. The World Health Organization (WHO) estimated that 250000 to 500000 deaths occur due to influenza A and B viruses annually (3). Influenza A and B viruses belong to the Orthomyxovirus family which possesses eight segmented single-stranded RNA (4).

The influenza viruses types can be distinguished on the basis of antigenic differences in nucleoprotein and matrix proteins (5). In addition, influenza A viruses are divided into several subtypes based on the antigenic dif ferences on the external glycoprotein, the hemagglutinin (HA), and the neuraminidase (NA) proteins (6). Until now 16 HA [H1-H16], and 9 NA [N1-N9] subtypes have been detected (7). HA and NA proteins of influenza type B are more stable than the type A, HA, and NA (5). Co-infection of influenza $\mathrm{A} / \mathrm{H} 1 \mathrm{~N} 1$ and $\mathrm{A} / \mathrm{H} 3 \mathrm{~N} 2$ with influenza $\mathrm{B}$ have been demonstrated in human population (6).

Routine lab tests for the diagnosis of influenza are serology and antigen detection (1). The common methods for subtyping influenza viruses include growth of virus in cell culture (i.e. MDCK) or embryonated chicken eggs prior to typing and subtyping by hemagglutination inhibition (HI), Enzyme-Linked Immunosorbent Assay (ELISA), or immunofluorescence (IF) (5). The main limitations of these techniques are time-consuming, low sensitivity, and low specificity. The use of nucleic acid amplification techniques has been found to be more sensitive for determining the type and subtype than the standard tissue culture (1).

\section{Objectives}

To date there is no report of epidemiological description of influenza viruses in Khuzestan province. Therefore for the present study the reverse transcription RTPCR assay was used for typing and subtyping influenza viruses in clinical samples during 2009-2010. Khuzestan province with the capital city of Ahwaz is located in the southwest of Iran. The population of Khuzestan province is about 4.5 million.

\section{Patients and Methods}

\subsection{Virus Strains and Clinical Specimens}

The study was approved by the Ethical Committee of Ahvaz Jundishapur University of Medical Sciences. The decision to admit patients for this study was performed according to the clinical condition of patients. Patients who fulfilled the case definition criteria in province of Khuzestan, Iran during March 2009 to February 2010 were included in this study.

Stock strains of influenza A and influenza B virus were obtained from the virology department of Public Health School, Tehran University Medical Science. The viruses used were the A/New Caledonia/20/99 H1N1, A/Panama/2007/99 H3N2, and B/Shangdong/7/97.

Nasopharyngeal swab specimens were obtained by physicians by a Dacron swab with a plastic shaft from 655 patients with influenza-like symptoms including fever, coughing, rhinorrhea, myalgia, arthralgia, and diarrhea. Patients' age was between 1 month and 85 years with the average age of $25.07 \pm 18.24$. The most suspected patients with flu-like symptoms were observed from Ahvaz (49.5\%), and the lowest cases were seen in Baghmalek (0.01\%). Clinical samples were taken within the 48 hours of initial symptoms. All the clinical samples were collected in the transport median (Copan Italia, Brescia, Italy) containing Hank's Balanced Salts, Bovine Serum, Albumin L-Cysteine, Gelatin Sucrose, L-Glutamic Acid, HEPES Buffer, Vancomycin, Amphotericin B, Celestin, Phenol Red. All the samples were stored at $-70 \mathrm{C}$ prior to the test.

\subsection{Nucleic Acid Extraction and cDNA Synthesis}

Viral RNA was extracted from $200 \mu$ of the each clinical sample using the High Pure Viral Nucleic Acid Kit (Roche Diagnostics, Mannheim, Germany) according to the manufacturer's instruction. The RNA was immediately kept at $-70{ }^{\circ} \mathrm{C}$. Complementary DNAs synthesis was performed using M-MLV reverse transcriptase (Fermentas, Burlington, Canada), and random hexamer primers (Fermentas, Burlington, Canada) according to the manufacturer's instructions.

\subsection{Polymerase Chain Reaction}

PCR was performed for four different reactions separately including influenza $\mathrm{A}, \mathrm{H} 1 \mathrm{~N} 1, \mathrm{H} 3 \mathrm{~N} 2$, and $\mathrm{B}$ viruses. Initially PCR test was performed for the determination of influenza A and B viruses, later the samples with positive results for influenza $A$ virus were tested for the detection of influenza $\mathrm{A} / \mathrm{H} 3 \mathrm{~N} 2$, and $\mathrm{A} / \mathrm{H} 1 \mathrm{~N} 1$. For the determination of influenza A virus the matrix primers, and for influenza $B$ virus the nucleoprotein primers were used ( Table 1). For influenza A subtypes the hemagglutinin gene was used ( Table 1 ).

$6 \mu \mathrm{l}$ of cDNA was added to $19 \mu \mathrm{l}$ of master mix containing $1 \mathrm{x}$ PCR buffer, 1.5mM MgCl2, 0.2mM dNTPs (Fermentas, Burlington, Canada), 1.5 U Taq polymerase enzyme (CinnaGen, Tehran, Iran), and $0.25 \mathrm{mM}$ of each primers (Bioneer, Seoul, South Korea). 
Table 1. Primers Used for the Typing and Subtyping of Influenza Viruses

\begin{tabular}{|c|c|c|c|c|}
\hline Name & Sequence $\left(5^{\prime} \rightarrow 3^{\prime}\right)$ & Gene Target-Nucleotide Position & $\begin{array}{l}\text { A mplicon } \\
\text { (bp) }\end{array}$ & Reference \\
\hline Flu-M-F & GACCRATCCTGTCACCTCTGAC & $91 \rightarrow 112$ & & (8) \\
\hline Flu-M-R & AGGGCATTYTGGACAAAKCGTCTA & $196 \rightarrow 173$ & 106 & (8) \\
\hline NP-B-For & ATAGGAAGAGCAATGGCAGACAGAG & $72-796$ & & (8) \\
\hline H1-A-For & CCGACTATGAGGAACTGAGGGAG & $335-375$ & & (9) \\
\hline H1-A-Rev & TCGCATCACATTCATCCATTG & $857-877$ & 543 & (9) \\
\hline H3-A-For & TGAACGTGACTATGCCAAACAATG & $547-570$ & & (9) \\
\hline H3-A-Rev & CGTATTTTGAAGTAACCCCGAGGA & $815-838$ & 292 & (9) \\
\hline
\end{tabular}

Amplification was performed for 35 cycles. The PCR reaction mixture was subjected to thermal cycler (Techne, Cambridge, UK) within the initial program at $94^{\circ} \mathrm{C}$ for 5 minutes, as follows: denaturation for $45 \mathrm{sec}$ at $94^{\circ} \mathrm{C}$, hybridization at $51^{\circ} \mathrm{C}$ (for MA), $54^{\circ} \mathrm{C}$ (for NP-B primers), $52.5^{\circ} \mathrm{C}$ (for $\mathrm{H} 1$ ), and $54.5^{\circ} \mathrm{C}$ (for $\mathrm{H} 3$ primers) for $45 \mathrm{sec}$, elongation at $72^{\circ} \mathrm{C}$ for $45 \mathrm{sec}$, and a final extension at $72^{\circ} \mathrm{C}$ for $7 \mathrm{~min}$ (9). PCR products were visualized by ethidium bromide following electrophoresis on $2 \%$ agarose gel.

Figure 1. Agarose Gel Electrophoresis of RT-PCR Products for Influenza Typing

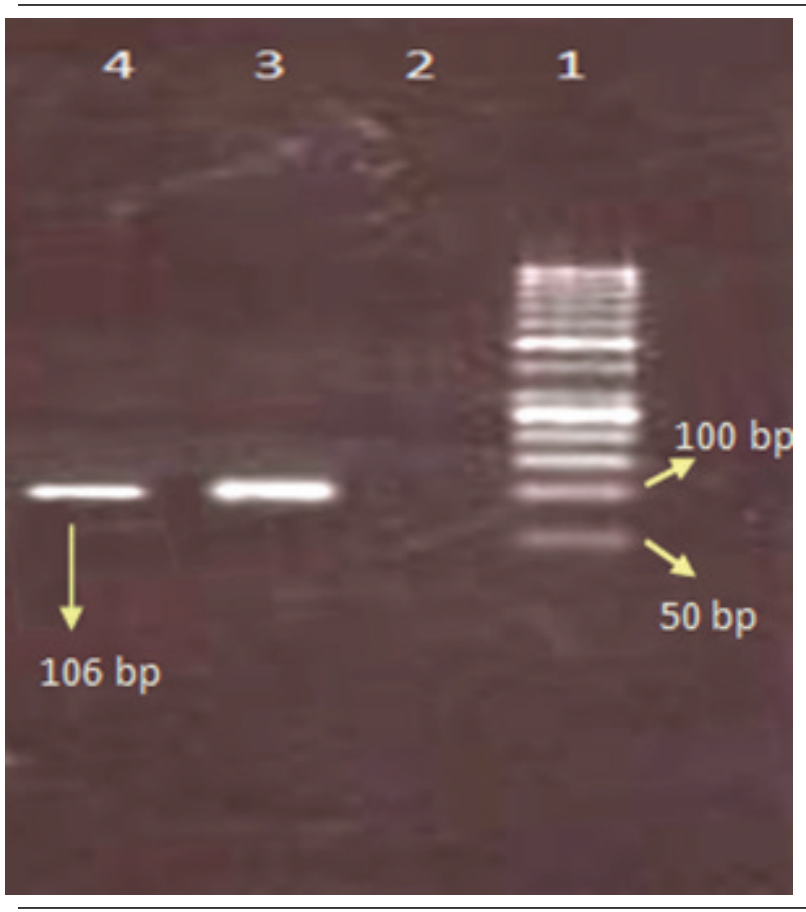

Lane 1: 50-bp DNA size marker, Lane 2 negative control, Lane 3 positive control, Lane 4: positive sample influenza type

\subsection{Statistical Test}

Statistical test was performed using SPSS version 17.0 (SPSS Inc, Chicago, Illinois).

Comparisons were performed between male and female using $X 2$ test in patients with positive and negative results for influenza. $P<0.05$ was considered statistically significant.

\section{Result}

The total prevalence of seasonal influenza A and B viruses was $11.29 \%$. Of 655,69 (10.53\%) samples had positive results for human influenza A virus, and 5 (0.7\%) samples had positive results for influenza B. Of those 69 samples with positive results for influenza A virus, 45 (6.8\%) belonged to $\mathrm{H} 3 \mathrm{~N} 2$, and 24 (3.6\%) to H1N1 subtypes. Agarose gel electrophoresis of PCR products are shown in Figures $1,2,3$, and 4 . The sample positive included $49 \%$ males and $51 \%$ females ( Table 2 ). The highest prevalence of seasonal influenza observed in Ahvaz city 4\% (27), and Mahshahr city $2.5 \%$ (19). Although, influenza A and B were not detected in Masjedsoleiman, Shooshtar, Izeh, Baghmalek, and Khoramshar cities (Figure 5).

Figure 2. Agarose Gel Electrophoresis of RT-PCR Products for Influenza Typing

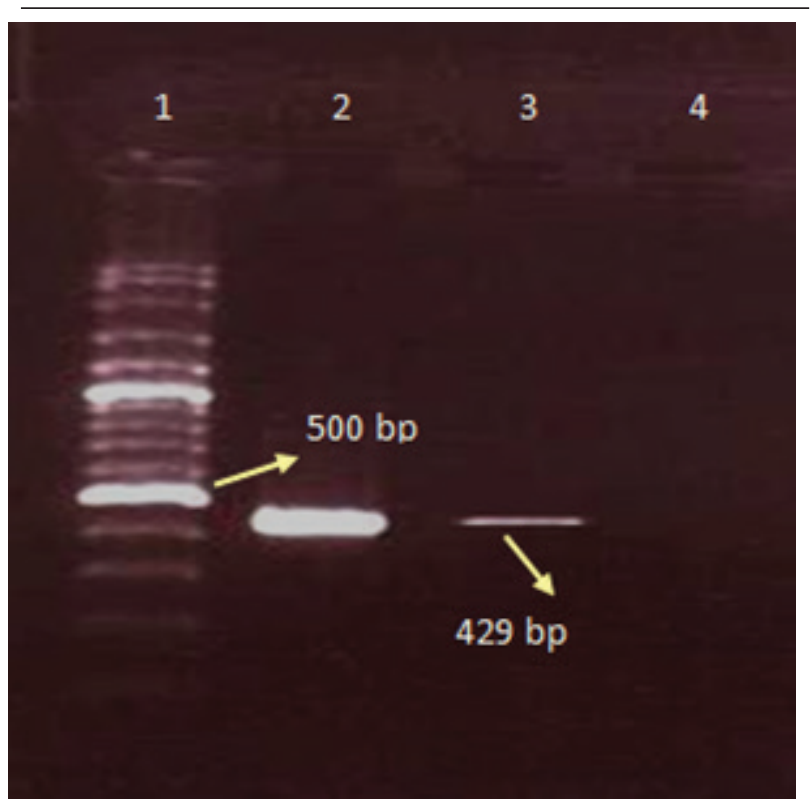

Lane 1: 100-bp DNA size marker, Lane: 2 positive control, Lane 3: influenza type B, Lane 4: negative control. 
Figure 3. Agarose Gel Electrophoresis of RT-PCR Products for Influenza Subtyping.

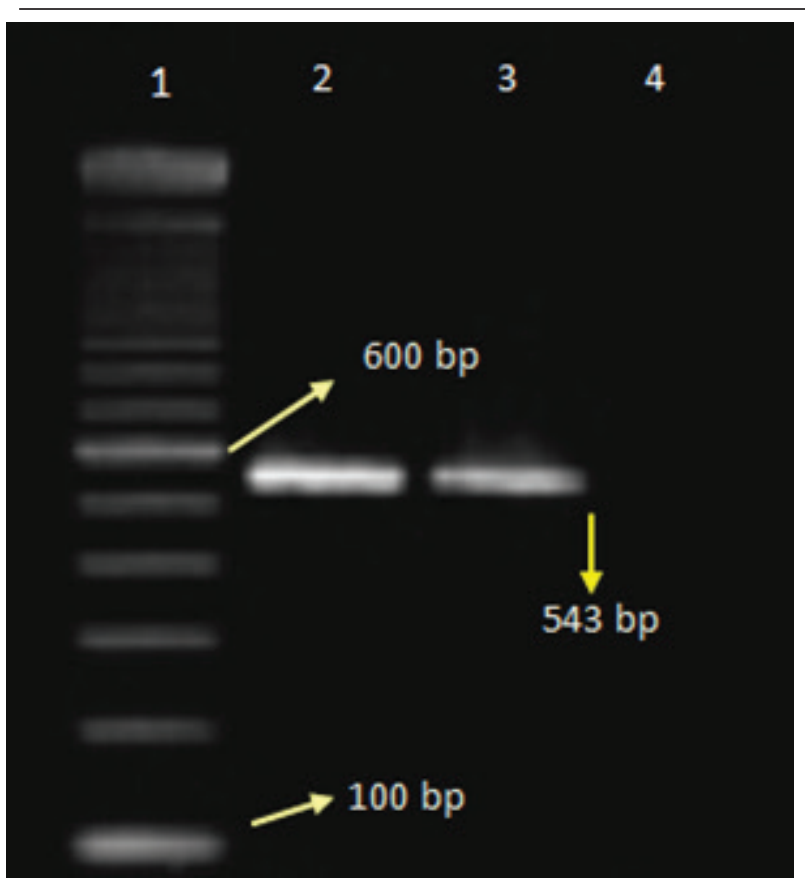

Lane 1: 100-bp DNA size marker, Lane: 2 positive control, Lane3: influenza H1-A, Lane 4: negative control.

Figure 4. Agarose Gel Electrophoresis of RT-PCR Products for Influenza Subtyping (H3-A)

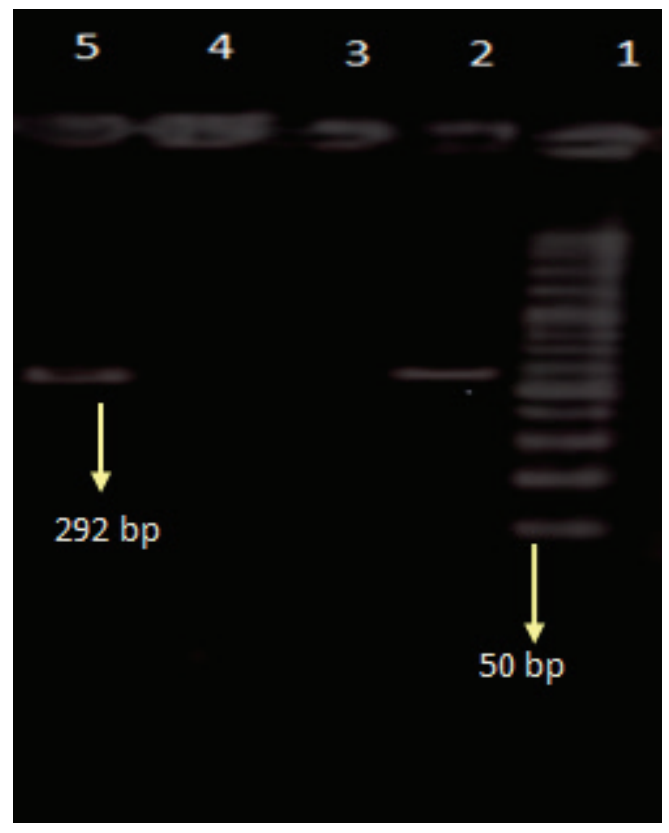

Lane 1: 50-bp DNA size marker, Lane 1: positive control, Lane 3: negative control, Lane 4: negative sample, Lane 5 positive sample

The average age of patients with positive results for influenza viruses was $20.18 \pm 16.22$ years old, compared to $25.87 \pm 18.80$ years old for those with negative results for influenza viruses.

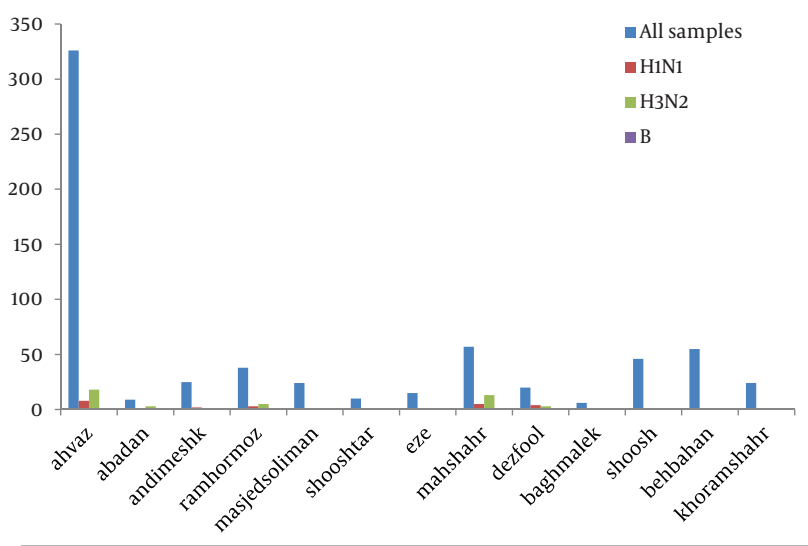

Figure 5. Distribution of Influenza Positive Specimens in Khuzestan

Most positive cases were found in patients aged less than 20 years. The duration of seasonal influenza was 7 months (Figure 2). The peak of seasonal influenza was between October and December 2009. The first cases were observed during mid August (Figure 6).

Table 2. General Characteristics of Specimens

\begin{tabular}{|llllll|}
\hline & \multicolumn{2}{c}{ Spimens, } & \multicolumn{2}{c}{ Type } & \multicolumn{2}{l}{ Subtype A } \\
\hline Age, $\mathbf{y}$ & & Infuenza A & Ifluenza B & H1N1 & H3N2 \\
\hline 0-10 & 138 & 22 & 1 & 4 & 18 \\
\hline $\mathbf{1 1 - 2 0}$ & 148 & 26 & 0 & 13 & 13 \\
\hline $\mathbf{2 1 - 3 0}$ & 160 & 12 & 1 & 3 & 9 \\
\hline $\mathbf{3 1 - 4 0}$ & 85 & 4 & 0 & 2 & 2 \\
\hline $\mathbf{4 1 - 5 0}$ & 49 & 4 & 1 & 1 & 3 \\
\hline $\mathbf{5 1 - 6 0}$ & 41 & 1 & 1 & 1 & 0 \\
\hline $\mathbf{7 6 0}$ & 31 & 0 & 1 & 0 & 0 \\
\hline Total & 652 & 69 & 5 & 24 & 45 \\
\hline Gender & & & & & \\
\hline Male & 354 & 33 & 2 & 12 & 21 \\
\hline Female & 301 & 36 & 3 & 12 & 24 \\
\hline Total & 655 & 69 & 5 & 24 & 45 \\
\hline
\end{tabular}

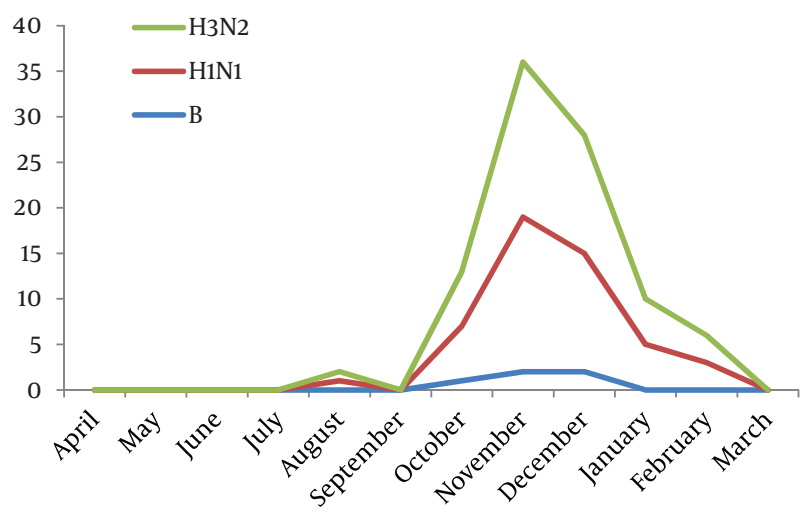

Figure 6. Monthly Distribution of Influenza Positive Specimens 


\section{Discussion}

Confirming the diagnosis of influenza with rapid tests such as RT-PCR is important for the clinical management to reduce the disease severity, and the early use of antiviral drugs (10). Furthermore, rapid diagnosis and accurate identification of current strains of influenza virus have epidemiological value. Another value of a rapid laboratory diagnosis that cannot be underestimated is for subsequent annual vaccine. Every year the WHO recommends vaccine strains for the forthcoming seasonal influenza, and for preventing epidemics based on the surveillance data gathered worldwide (11).

In this study the prevalence of type and subtypes of human influenza A were assessed in Khuzestan province of Iran during 2009-2010. There are several reports on the prevalence of influenza in Iran. In Tehran, Soltani and colleagues reported in 2007 that 12 of 57 samples (21\%) had positive results for human influenza using RT PCR, which 7 were A/H3N2, 3 were A/H1N1, and 2 were B Subtypes (10). Mousavi et al. in 2008-09 in Tehran reported that of 142 samples, 17 had positive results for seasonal influenza virus, which 15 were H1N1, and only $2 \mathrm{H} 3 \mathrm{~N} 2$ were detected, and influenza type B was not identified (12).

In Malaysia, Zainah Saat and colleagues in 2009 reported13.5\% (227/1,678) seasonal Influenza, which $78.0 \%$ (177/227) influenza A, and 22.0\% (50/227) influenza B were typed and subtyped by hemagglutination inhibition (HAI) assays (11). In Western Australia Dale Carcione et al. reported 11.2\% seasonal influenza by RT PCR in 2009 (13). Ji Rong Yang and colleagues in 2009 in Taiwan reported $14.11 \%$ seasonal influenza which (13.4\%) H3N2, 12 (0.7\%) $\mathrm{H} 1 \mathrm{~N} 1$ and 1 (0.06\%) influenza B viruses were identified by real-time RT-PCR (2). Our findings showed that the rate of positive influenza virus was the same as the range described in Malaysia, Taiwan, and Western Australia studies $(2,11,13)$.

The prevalence of positive seasonal influenza among male (49\%) and female (51\%) was not found significant (P $>0.05$ ). Dingle et al. reported that the highest attack rate of seasonal influenza was observed in school-age children, and they might have a critical role in disseminating seasonal influenza (14). However in the present study the highest prevalence of seasonal influenza was observed in two age groups: one group with 31\% (23/138) less than 10 years old, and the second group with 37\% (28/148) aged 1120 years old. The lowest prevalence of seasonal influenza was observed among patients over 60 (1/31) (3\%).This finding revealed the increased distribution of the seasonal influenza viruses in young age groups during 2009-2010. Seasonal influenza occurs in winter in the Northern hemisphere, but its peak of activity time is varying. The "peak month of seasonal influenza activity" occurs in January or later (15). The Center for Disease Control (CDC) reported that, during 2009-2010 seasonal influenza began earlier causing pandemic H1N1, and activity peaked in
October and next declined in January. In agreement with this finding in the present study the month of influenza peak activity was observed during October and December 2009, which seems to be correlated with the US CDC surveillance data (15).

This study has some limitations, including lacks of patients' demography such as history of allergic disease, pregnant woman, patients with renal failure or cardiac problem, and individual with immune deficiency which requires further investigation. The suspected influenza patients admitted in private clinics were not included in the present study. In this study $88.71 \%$ of samples, had negative results for influenza viruses. Besides, other viruses including Metapneumovirus (16), Adenovirus, Respiratory Syncytial virus, and Parainfluenza $(17,18)$ viruses which can cause the influenza-like symptoms were not studied in the present study. Finally, regarding to prevalence of influenza in Khuzestan, the immunization program could significantly decrease the number of the influenza infection, particularly among children and elderly.

\section{Acknowledgements}

The authors wish to thank the Research Center of Infectious and Tropical Diseases, Ahvaz Jundishapur University of Medical Sciences. As well we would like to thank Dr. Mokhtari Azad from virology department of Public Health School, Tehran University of Medical Science for providing the positive control samples.

\section{Financial Disclosure}

Infectious and Tropical Disease Research Center, Ahvaz Jundishapur University of Medical Sciences, Ahvaz, Iran.

\section{Funding/Support}

None declared.

\section{Authors' Contribution}

None declared.

\section{References}

1. Herrmann B, Larsson C, Zweygberg BW. Simultaneous detection and typing of influenza viruses $A$ and $B$ by a nested reverse transcription-PCR: comparison to virus isolation and antigen detection by immunofluorescence and optical immunoassay (FLU OIA). JClin Microbiol. 2001;39(1):134-8.

2. Yang JR, Lo J, Ho YL, Wu HS, Liu MT. Pandemic H1N1 and seasonal $\mathrm{H} 3 \mathrm{~N} 2$ influenza infection in the human population show different distributions of viral loads, which substantially affect the performance of rapid influenza tests. Virus Res. 2011;155(1):163-7.

3. World Health Organization. Influenza (Seasonal). Available from: http://www.who.int/mediacentre/factsheets/fs211/en/.

4. Li X, Qi X, Miao L, Wang Y, Liu F, Gu H, et al. Detection and subtyping of influenza A virus based on a short oligonucleotide microarray. Diagn Microbiol Infect Dis. 2009;65(3):261-70.

5. Wright KE, Wilson GA, Novosad D, Dimock C, Tan D, Weber JM. Typing and subtyping of influenza viruses in clinical samples by 
PCR. J Clin Microbiol.1995:33(5):1180-4.

6. Falchi A, Varesi L, Arena C, Leveque N, Renois F, Blanchon T, et al Co-circulation of two genetically distinct sub-groups of $\mathrm{A} / \mathrm{H} 3 \mathrm{~N} 2$ influenza strains during the 2006-2007 epidemic season in Corsica Island, France. J Clin Virol. 2009;45(3):265-8.

7. Krumbholz A, Philipps A, Oehring H, Schwarzer K, Eitner A, Wutzler $\mathrm{P}$, et al. Current knowledge on PB1-F2 of influenza A viruses. Med Microbiol Immunol. 2011;200(2):69-75.

8. Yang Y, Gonzalez R, Huang F, Wang W, Li Y, Vernet G, et al. Simultaneous typing and HA/NA subtyping of influenza $A$ and $B$ viruses including the pandemic influenza A/H1N1 2009 by multiplex real-time RT-PCR.J Virol Methods. 2010;167(1):37-44

9. Shahidi M, Kheiri MT, Amini-Bavil-Olyaee S, Hosseini M, Moattari A, Tabatabaeian M, et al. Molecular and phylogenetic analysis of human influenza virus among Iranian patients in Shiraz, Iran. Med Virol. 2007;79(6):803-10.

10. Soltani Z, Hosseini M, Shahidi M, Hedayati M, Kheiri MT. Molecular analysis of human influenza virus in Tehran, Iran. Intervirology. 2009;52(2):63-7.

11. Saat Z, Abdul Rashid TR, Yusof MA, Kassim FM, Thayan R, Kuen LS, et al. Seasonal influenza virus strains circulating in Malaysia from 2005 to 2009. Southeast Asian J Trop Med Public Health 2010;41(6):1368-73.

12. Mousavi SF, Tavassoti Kheiri M, Hosseini SM, Taghizadeh M, Fotouhi F, Heydarchi B. Phylogenetic Comparison of Influenza
Virus Isolates from Three Medical Centers in Tehran with the Vaccine Strains during 2008-2009. Iran J Med Sci. 2011;36:172-177.

13. Carcione D, Giele C, Dowse GK, Mak DB, Goggin L, Kwan K, et al. Comparison of pandemic (H1N1) 2009 and seasonal influenza Western Australia, 2009. Emerg Infect Dis. 2010;16(9):1388-95.

14. Dingle JH, Badger GF, Jordan Jr WS. Illness in the Home. A Study of 25,000 Illnesses in a Group of Cleveland Families. Illness in the Home. A Study of 25, 000 Illnesses in a Group of Cleveland Families. 1964.

15. Novel influenza A (H1N1) and seasonal Influenza virus surveillance, New Zealand, April-July 2009. MMWR Morb Mortal Wkly Rep. 2009;58(19):918-21.

16. Bouscambert-Duchamp M, Lina B, Trompette A, Moret H, Motte J, Andreoletti L. Detection of human metapneumovirus RNA sequences in nasopharyngeal aspirates of young French children with acute bronchiolitis by real-time reverse transcriptase PCR and phylogenetic analysis. J Clin Microbiol. 2005;43(3):1411-4.

17. Coiras MT, Perez-Brena P, Garcia ML, Casas I. Simultaneous detection of influenza A, B, and C viruses, respiratory syncytial virus, and adenoviruses in clinical samples by multiplex reverse transcription nested-PCR assay. J Med Virol. 2003;69(1):132-44.

18. Louie JK, Hacker JK, Gonzales R, Mark J, Maselli JH, Yagi S, et al. Characterization of viral agents causing acute respiratory infection in a San Francisco University Medical Center Clinic during the influenza season. Clin Infect Dis. 2005;41(6):822-8. 